\title{
The enigma and complexity of landscape dynamics in Chinese deserts: From case studies to big data
}

\author{
Peng Liang, H. Li, Y. Zhou, X. Fu, L. Mackenzie and D. Zhang
}

\begin{abstract}
We analyze the recent progress in eolian surface processes and landscape dynamics in Chinese deserts. These diverse eolian studies, including paleoenvironmental reconstructions, advances in dating techniques, and clarification of sediment provenance, highlight the complexity of desert landscape evolution.
\end{abstract}

\begin{abstract}
Drylands occupy $\sim 41 \%$ of the global land surface and are home to more than two billion people (Reynolds et al. 2007). In recent decades, global warming and intensified human activities have exacerbated the environmental degradation or desertification in drylands, threatening nations' economies and sustainable development. Additionally, deserts are an important yet poorly understood component of the Earth system, with dust released from these regions affecting the global biogeochemical cycle and climate. Early-career researchers (ECRs) at Zhejiang University and elsewhere in China are currently investigating sedimentary archives from the interior of Chinese deserts in the eastern Asian desert belt (Fig. 1) to ex plore complex landscape dynamics through time.
\end{abstract}

\section{Paleoenvironmental signals archived} in the eastern Chinese deserts

The large semi-stabilized sandy lands in the deserts of eastern China are located near the northern extent of the East Asian summer monsoon (Fig. 1). Stratigraphic sequences from the sandy lands record repeated periods of dune activation and stabilization through alternating eolian (windblown) sands and paleosols (buried soils).
Dune stabilization processes are usually a landscape response to increased precipitation associated with enhanced summer monsoons, while increased eolian activity and dune activation occurs during periods of drought. These alternating sequences are a direct and sensitive record of past monsoon variability. Yang et al. (2019) found that a dark brown (Munsell soil color 10YR 4/3) paleosol began to develop at 14.5 thousand years before present ( $k y r$ BP) and lasted until 2 kyr BP in the Hulunbeier Sandy Land, while stronger pedogenesis (i.e. soil formation) occurred during 9-5 kyr BP. Eolian sequences from the Hunshandake Sandy Land recorded dune stabilization processes from 9.6 to 3.0 kyr BP, though localized eolian events occurred at the same time (Fig. 2). Although the paleolandscape in the eastern sandy lands shows a high degree of spatial heterogeneity, dunes were generally stabilized and eolian activity was suppressed from 7.5 to 3.5 kyr BP in the mid-Holocene (Fig. 2; Yang et al. 2019). These geological records from dune sequences are generally consistent with paleoclimate simulations, which indicate that northern China received higher summer monsoon precipitation during the mid-Holocene than during the pre-industrial period, although the moisture transport pathway is more complex in western Chinese deserts (Feng and Yang 2019).

Spatial heterogeneity of the landscape leads to an unavoidable uncertainty when interpreting geological signals from eolian stratigraphic sequences. Liang and Yang (2016) investigated drivers of landscape heterogeneity at different scales in the Maowusu Sandy Land, northern China (Fig. 1). They found that climate and largescale agricultural reclamation affect regional landscape patterns in the Maowusu Sandy Land, whereas microtopography and river networks drive landscape heterogeneity at a local scale. The landscape response to declining wind strength in the Maowusu Sandy Land from 1981 to 2016 shows a significantly out-of-step pattern between the western and eastern regions, arising from different regional climates and land-use histories (Liang and Yang 2016), highlighting the complexity of landscape dynamics in drylands.

The eolian processes at the dune scale also play an important role in the interpretation of paleoenvironmental records from dune deposits. The dune stabilization process is assumed to be mainly caused by precipitation-induced vegetation expansion.

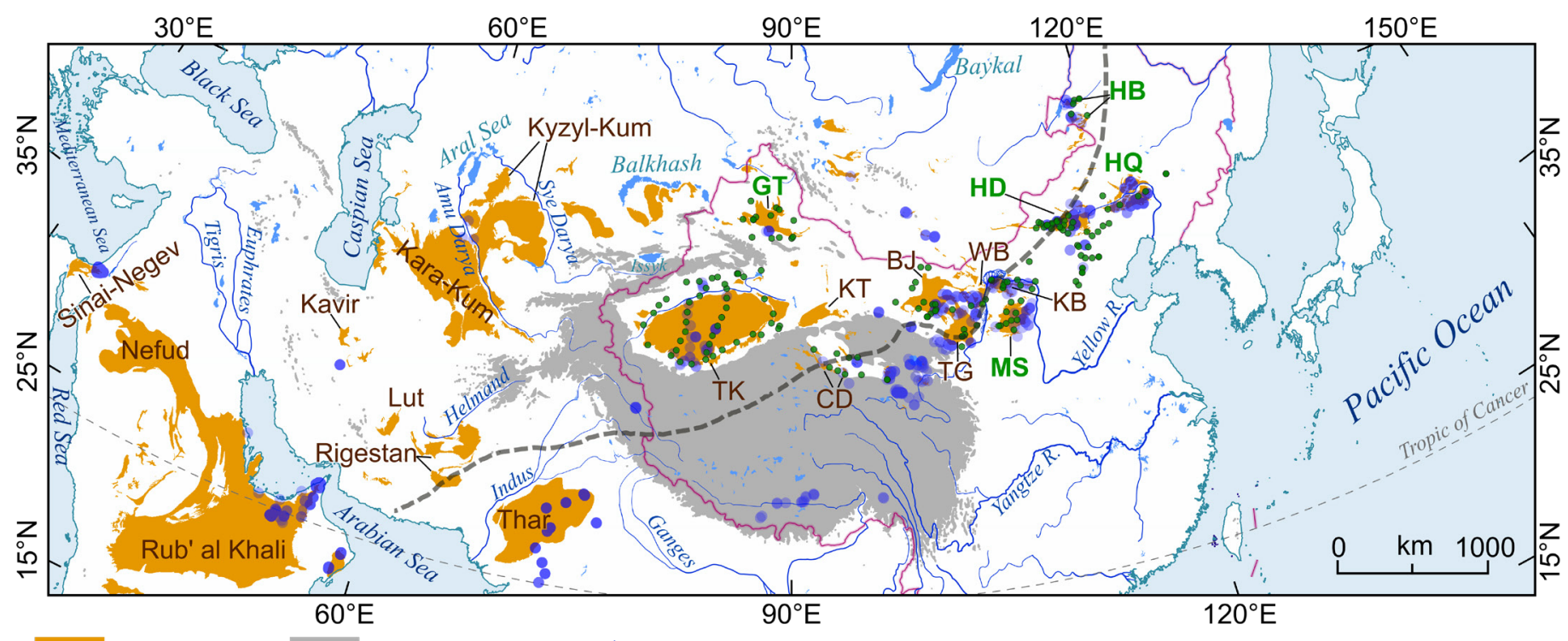

Dune fields

Altitude $>3000 \mathrm{~m}$

- Published sections

- Published surface sand samples

Figure 1: Distribution of Asian deserts, major rivers, and published data in the growing database. The thick dashed line indicates the boundary of the Asian summer monsoon. Active sand seas: Taklamakan (TK); Kumtagh (KT); Chaidamu (CD); Badain Jaran (BJ); Tengger (TG); Wulanbuhe (WB). Semi-stabilized sandy lands: Gurbantunggut (GT); Maowusu (MS); Kubuqi (KB); Hunshandake (HD); Horqin (HQ); Hulunbeier (HB). 

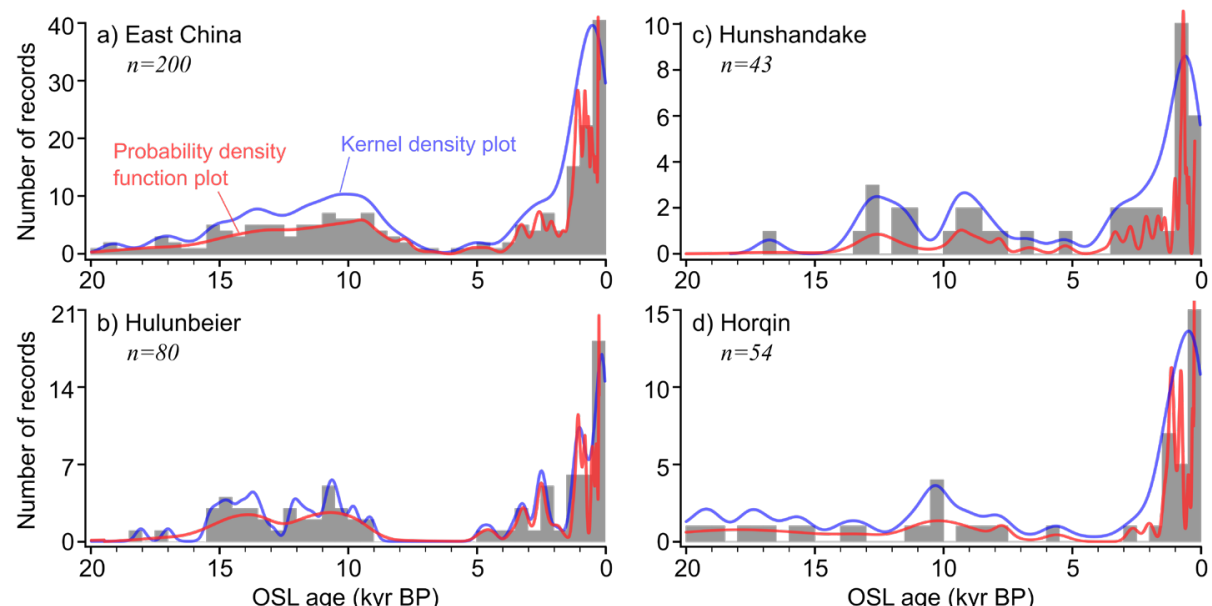

Figure 2: Eolian events represented by the frequency of optically stimulated luminescence (OSL) ages from the eastern sandy lands of northern China. The gray rectangles are OSL age histograms, and the bin size is $0.5 \mathrm{kyr}$. Data are from Li and Yang (2016) and Yang et al. (2019) with new data added.

However, a new case study investigating the transition from barchan (crescentshaped sand dune) to parabolic dunes in the Maowusu Sandy Land demonstrated that the reduction of wind strength can lower the sand flux rate and dune height, which allows for vegetation establishment and dune transformation (Zhang et al. 2020). This research suggests that some mismatches between dune activity and moisture variability could be reconciled through a better understanding of past wind regimes.

\section{Improved dating techniques for} paleoenvironmental reconstructions Over the past 20 years, optically stimulated luminescence (OSL) dating has become a well-established Quaternary geochronometer, particularly for eolian sediments, and is arguably the most important tool for desert paleoenvironmental research. A series of luminescence dating procedures for K-feldspar, a ubiquitous mineral in natural sediments, has recently been developed using eolian and fluvial samples from Chinese deserts (Fu et al. 2015; Fu et al. 2018). These techniques considerably extend upper and lower dating limits and improve dating accuracy. The ability to analyze raw luminescence dating data has also been enhanced by a newly developed software "Luminescence Dose and Age Calculator (LDAC v1.0)" (Liang and Forman 2019; https://github.com/Peng-Liang/LDAC), which can maintain, archive, and synthesize basic OSL data, apply appropriate statistical models, calculate environmental dose rate, and render statistically significant final ages. This self-contained tool for luminescence dating allows for inter-laboratory OSL age comparisons and promotes more robust datasets for landscape-dynamics research in drylands and beyond. OSL dating of eolian sands has produced over 300 age records from dunes in China, which were recently compiled as part of the INQUA Dunes Atlas chronologic database (Li and Yang 2016; https://www.dri.edu/inquadunesatlas/). This primary dataset collated by ECRs has helped to build a picture of the eolian history in Chinese deserts since the Last Glacial Maximum, showing that the eolian events identified by the frequency of OSL ages increased during the last deglaciation and late Holocene but are mostly dormant during the mid-Holocene (Fig. 2). However, our understanding of eolian activity at the glacial-interglacial timescale is still unclear due to the lack of well-preserved and statistically meaningful archives older than $20 \mathrm{kyr}$ BP from desert interiors, limiting regional multi-site paleoenvironmental reconstruction (Li and Yang 2016).

\section{Sediment provenance and surface processes}

Identifying sediment provenance can yield insights into understanding the complexity of past and present landscape dynamics in deserts. Sediment sources in the Taklamakan Desert, Badain Jaran Desert, Kubuqi Desert, and Maowusu Sandy Land were investigated by combining geochemical compositions of the sand with geomorphic analysis ( $\mathrm{Hu}$ and Yang 2016; Liu and Yang 2018; Jiang and Yang 2019; Zhou et al. 2020). Results show that the dust fraction $(<63 \mu \mathrm{m})$ in dune sands from the Taklamakan Desert varies from $0.44 \%$ to $21.7 \%$ and can be traced to the Kunlun and Tianshan Mountains by their geochemical and sedimentological characteristics. However, the sand particles (>63 $\mu \mathrm{m}$ ) were predominantly sourced from the Kunlun Mountains in the south and transported via fluvial processes (Jiang and Yang 2019; Zhou et al. 2020). These results suggest that dust particles within deserts have independent provenance, which is consistent with the low dust-generation potential from sand saltation and wind abrasion found in wind-tunnel experiments (Adams and Soreghan 2020). Similarly, fluvial processes provide sand to the Badain Jaran Desert ( $\mathrm{Hu}$ and Yang 2016), the Kubuqi Desert, and the Maowusu Sandy Land (Liu and Yang 2018) by transporting loose sediments from nearby mountains to the desert basins. These primary dune-building sediments are then further mixed via local eolian processes (Liu and Yang 2020).

\section{Future work: moving to big data}

The aforementioned case studies have greatly enriched our understanding of the landscape dynamics and surface processes in deserts of China and beyond, but a more comprehensive and continental-scale picture is still lacking. Paleoenvironmental reconstructions based on single-site dune deposits or sequences alternating between lacustrine, eolian sands, and paleosols in deserts inevitably contain uncertainties. These uncertainties mainly arise from the spatial heterogeneity of the eolian landscape (Liang and Yang 2016), the episodic/ discontinuous eolian sand deposition features with possible eolian erosion (Forman 2015), and the generally non-linear response between eolian depositional processes and climate fluctuations (Yang et al. 2019). A big-data concept incorporating a continental-scale database using the substantial paleoenvironmental records from Chinese deserts could be introduced to overcome these difficulties and complexities. This database is currently under construction (Fig. 1) and will include sedimentary sequences that contain well-vetted geomorphic context information, stratigraphic descriptions, proxies (such as grain size, magnetic susceptibility), and relevant ages. A comprehensive and well-organized database that includes multiple physical and chemical indices of surface dune sand, such as grain size, geochemical composition, and petrology, is also required to advance sand provenance studies. These increasingly large and high-dimensional datasets and data-driven computations are a promising avenue to enhance our understanding of eolian processes and the Earth system from a big-data perspective, especially with the aid of machine learning algorithms. However, more in-depth field studies are still indispensable.

\section{ACKNOWLEDGEMENTS}

Our current work was supported mainly by the Ministry of Science \& Technology of China (2017FY101001) and the National Natural Science Foundation of China (41672182; 42001003; 41430532). Sincere thanks are extended to the early-career researchers whose work we have cited, including Dr. Fangen Hu, Qianqian Liu, Qida Jiang and Yingying Feng. We also thank Dr. Ziting Liu and Wancang Zhao for enriching the ongoing database.

\section{AFFILIATION}

School of Earth Sciences, Zhejiang University, Hangzhou, China

\section{CONTACT}

Peng Liang: PLiang@zju.edu.cn

\section{REFERENCES}

Adams SM, Soreghan GS (2020) Geology 48: 1105-1109 Feng Y, Yang X (2019) J Geogr Sci 29: 2101-2121 Forman SL (2015) Front Earth Sci 3: 3

Fu X et al. (2015) Quat Geochronol 30: 161-167 Fu X et al. (2018) Quat Geochronol 47: 1-13 Hu F, Yang X (2016) Quat Sci Rev 131, Part A: 179-192 Jiang Q, Yang X (2019) J Geophys Res Earth Surf 124 $1217-1237$

Li H, Yang X (2016) Quat Int 410: 58-68

Liang P, Forman SL (2019) Ancient TL 37: 21-40

Liang P, Yang X (2016) Catena 145: 321-333

Liu Q, Yang X (2018) Geomorphology 318: 354-374

Liu Q, Yang X (2020) J Desert Res 40: 158-168

Reynolds JF et al. (2007) Science 316: 847-851

Yang X et al. (2019) Sci China Earth Sci 62: 1302-1315

Zhang D et al. (2020) Earth Surf Process Landf 45: 2300-2313

Zhou Y et al. (2020) Geomorphology 375: 107560 